\title{
Digitalisation and Development: Issues for India and Beyond
}

\author{
Dibyendu Maiti, Fulvio Castellacci and Arne Melchior
}

\begin{abstract}
Information and communication technologies (ICTs) provide new opportunities and new challenges for developing economies. ICT adoption, digitalization and automation provide formidable new opportunities in terms of increased efficiency and productivity, the creation of new services and occupations and increased connectivity among agents. However, the extent to which developing economies are able to reap these potential benefits is contingent on a set of other social, economic and institutional dimensions. While economic growth and rising productivity are the major expected outcomes of digitalization, digital divides and related forms of exclusion and inequalities are commonly observed too. India, one of the largest economies in the world, with a remarkable pace of ICT diffusion, represents a relevant case to investigate the impacts of digitalization on economic development. The present book collects a series of novel contributions on this theme, studying the Indian experience in an international cross-country perspective. This introductory chapter presents background information on the Indian case, introduces the main themes on the relationships between ICTs, socio-economic development and digital divides and provides a summary and road map to the chapters included in the book. On the whole, the main message of this book is that the impact of ICTs is contingent upon other assets, capabilities and institutional conditions. National policies should therefore not only promote digitalization as such but also ensure its co-evolution and complementarity with a variety of other country-specific factors.
\end{abstract}

D. Maiti (凶)

University of Delhi, New Delhi, India

e-mail: dibyendu@econdse.org

F. Castellacci ( $\varangle)$

University of Oslo, Oslo, Norway

e-mail: fulvio.castellacci@tik.uio.no

A. Melchior $(\varangle)$

Norwegian Institute of International Affairs (NUPI), Oslo, Norway

e-mail: AM@nupi.no 


\section{Introduction ${ }^{1}$}

Innovations in information and communication technologies (ICTs) have brought revolutionary changes not only on the economic front but also in the social and personal areas of human life. ICTs initially originated from the fast technological developments in the semiconductor industry, in the telecommunication sector and, more recently, in a wide range of new services linked to multimedia and the Internet (Dalum et al. 1999; Castellacci 2006). Key technological trajectories within ICTs are currently represented by automation and the Internet. The convergence of these technological advances may arguably constitute the rise of a new "technological paradigm" (Freeman and Louça 2001).

A technological paradigm is a set of interrelated and pervasive innovations that increases productivity in many sectors of the economy (Dosi 1988; Freeman et al. 1982). The new technological paradigm based on ICTs may have important economic effects on growth, wealth and welfare in the near future, and it may lead to radical changes in firms' production structure and organizations, in the patterns of consumption and in institutional settings. Innovation studies have extensively investigated the emergence and diffusion of ICTs and particularly focused on the pervasive economic effects that these general-purpose technologies have on different sectors of the economy (Castellacci 2006, 2008).

One major question that is often discussed in this field relates to the consequences that the diffusion of ICTs has for catching up and developing economies. Does the new technological paradigm based on ICTs create new windows of opportunity or further obstacles for catching-up countries? The answer to this question is a matter of considerable controversy in the literature on innovation and economic development, and it is rather difficult to discuss because of the fundamental elements of uncertainty, complexity and unpredictability that it entails. It is possible to identify, by and large, two different positions.

The first is a more optimistic stand, which stresses the new windows of opportunity opened up for developing economies by the creation and diffusion of the new information and communication technologies. This position is founded upon the old argument in the catching-up literature of the "penalty of taking the lead" (Veblen 1915). According to this, developing countries may exploit their backward position by imitating and implementing advanced foreign technologies created by the leader economies and by rapidly investing in the new technologies. In the new era, less developed economies are less committed to the mass production technological paradigm prevailing in previous decades (in terms of investments in physical capital, machineries and infrastructures) so that they may find it easier to make the jump into the new technological system based on ICTs.

The rapid catching-up process of Asian NICs (Newly Industrialized Countries, such as Korea, Singapore and Taiwan) in the last few decades shows that the opportunities opened up by the diffusion of the ICT-based paradigm can indeed be successfully exploited by catching-up countries, provided that the development strategy

\footnotetext{
${ }^{1}$ Some of the initial text in Sect. 1 is based upon Castellacci (2006).
} 
that they pursue emphasizes the need to actively invest in the new technologies and in the related infrastructures and skills.

These successful cases, however, contrast with the general pattern of increasing disparities in income and technology levels that the world economy has experienced in the last few decades (Parayil 2005; Castellacci 2011). A large group of less developed economies, mostly in Africa, Asia and Latin America, have in fact been growing at a rather slow pace, and the technology and income gap has therefore significantly widened for many of them. Several countries have very low levels of technological capabilities, infrastructures and education and consequently find it hard to exploit their backwardness position by imitating ICT-related foreign advanced technologies.

There thus exists a second position in development research that is less optimistic with respects to the current and future prospects for innovation- and imitation-based growth. This is founded upon a strand of historically oriented studies on technological development, growth and catching up (Abramovitz 1986, 1994). Historical evidence indicates that economic development is far from being an automatic and easy process and that it is on the contrary very demanding and costly. This second stand therefore looks with greater concern at the social and institutional factors that may hamper the catching-up process. In this respect, it is argued that the new paradigm based on information and communication technologies is creating as many new obstacles for development as the opportunities it opens up. The process of creation of new technologies and its international diffusion is currently more difficult to exploit for catching-up countries, due to the greater requirement in terms of skills, competencies and capabilities that modern ICT-based global competition requires (Fagerberg and Godinho 2005). In particular, the international diffusion of technologies, which has been a major factor of catching up in previous decades, seems to have become more "difficult" and demanding over time (Fagerberg and Verspagen 2002).

The present book conceives these two arguments as largely complementary to each other, rather than opposite, as they look at different relevant aspects of the development process. By taking these two previous positions as a general starting point, the book investigates the new opportunities and further obstacles that the emergence of the new ICT-based technological paradigm creates for developing countries, particularly focusing on the case of India.

India, one of the largest economies in the world, with a remarkable pace of ICT diffusion, represents a relevant case to investigate the impacts of digitalization on economic development. Not only has India become the world's largest exporter of ICT-related services; the Indian Government has also made use of ICTs as a key policy strategy. For the sake of fast digitalization, the Indian government launched the important reform known as the "Digital India" project in July 2015. The project is having a total overlay of about 14 billion USD (or, Rupee 1 lakh crores) aimed at transforming the country into a knowledge economy by ensuring easy access to technology, infrastructure and government services to citizens. The Communications and IT Ministry sought to create business opportunities worth 1 trillion dollars through major impacts in IT/ITES, electronic, manufacturing and telecom sectors. The "Digital India" programme has sought to (i) provide high-speed Internet to common man, (ii) make all government services accessible to the population at large, and (iii) ensure 
digital empowerment of citizens. Besides, the "Aadhaar Scheme" was launched in January 2009 to integrate all citizens through the provision of biometric identification cards. Attempts were also made to provide direct benefits (like unemployment benefits, subsidies, public utilities, etc.) assisted by ICT in order to bypass intermediaries, avoid informality, detect cyber-crime, control border security and encourage online transactions so that the government could effectively pursue redistributive policies, preserve security and offer efficient public services delivery. Various other programmes have also been added to target and deliver specific programmes and group of people.

These recent development and policy efforts raise some important questions. First, to what extent does the access to ICT services enhance economic outcomes and performance in India? Second, how far has this reached across different social groups and regions of the country, and how has this affected economic and social inequalities in the country? Third, what is the success rate in terms of governance, control of corruption as well as contribution to social welfare and well-being? These issues are of crucial importance, and this book is set to investigate these questions by studying the Indian experience in a cross-country international perspective.

This introductory chapter is organized as follows. Sect. 2 provides background information on recent developments and economic patterns in India. Sect. 3 presents a brief overview of recent policy efforts and increasing trends towards the digitalization of the Indian economy, discussing why and how these are expected to affect economic growth, digital divides and social welfare in the future. Sect. 4 then summarises the themes and main results of the 14 studies collected in this book, and how these contribute to extant research and the policy debate on digitalization and development.

\section{India's Growth, Development and Well-Being ${ }^{2}$}

India has maintained a decent growth rate for the last two decades in spite of the global financial crisis. With an average Indian GDP growth rate about $7 \%$ in recent years, the current deceleration of growth in China has taken India from second tier to the top. The Indian growth rate was an impressive $8.2 \%$ in the first quarter of this financial year 2018 due to the strong performance of the manufacturing and agriculture sectors. This led to an increase in its lead over China to remain the fastest growing major economy of the world. According to a report by the Center for International Development at Harvard University, India, is expected to top the list of the fastest growing economies in the world for the coming decade, with a projected annual growth rate at $7.9 \%$. Figure 1 shows India's impressive increase in GDP growth rate, surpassing Brazil and China.

Despite India's remarkable growth performance, there are also some painful realities in terms of economic development. According to the World Bank, still one out five Indians is poor. According to the latest official figures in 2012, the poverty rate is

\footnotetext{
${ }^{2}$ Some information for this section is drawn from Agrawal and Maiti (2019).
} 


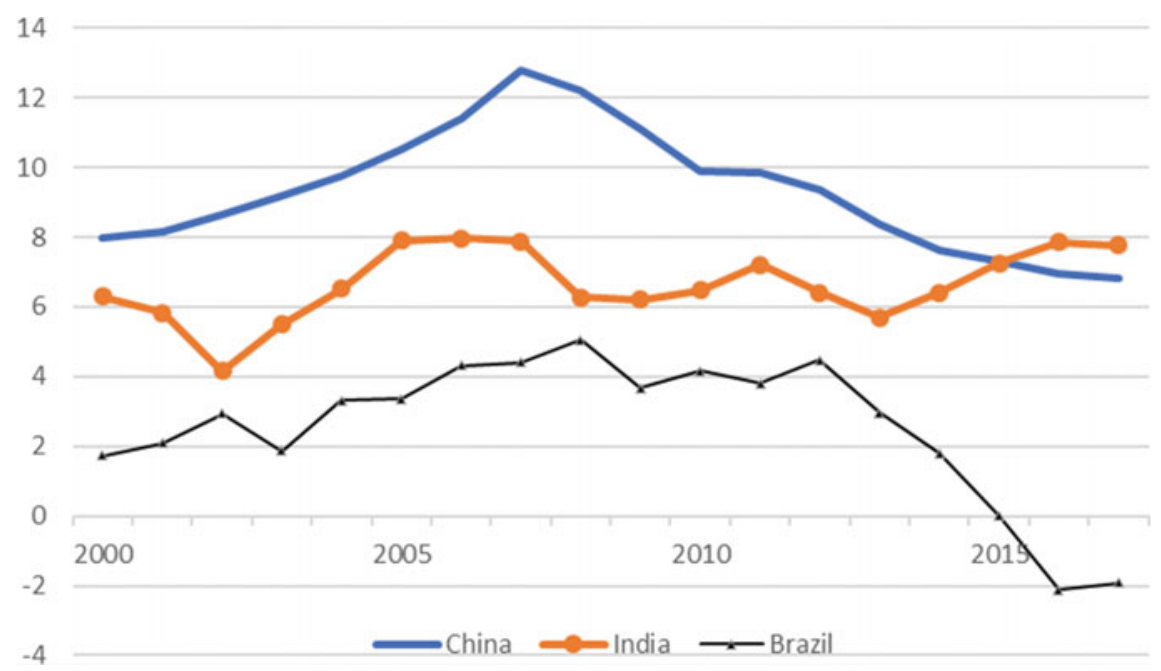

Fig. 1 GDP growth in India, China and Brazil, 2000-2017 (average of past 3 years). Source World Development Indicators, World Bank

$14 \%$ in urban areas but $25 \%$ in rural areas. More than $60 \%$ of poverty is concentrated in seven states in the country. According to the recent Global Hunger Index Report 2012 by the International Food Research Institute, India ranks 97th in Global Hunger Index. This suggests that the benefits of economic growth have not been percolated equally to every stratum of the income distribution.

Gainful and decent employment is the single largest problem in the country. According to the latest National Sample Survey Organisation (NSSO) report, more than $80 \%$ of the working population is still in the informal and unorganized sector, without having any right to obtain social security benefits. Unemployment is still a major issue in rural and urban areas, especially for unskilled workers, and hence, the term "jobless growth" has been defined as India's growth story. The official unemployment rate was just below 5\% in 2017, but a report by OECD found that over $30 \%$ of people aged 15-29 were not in employment, education or training. This is affected by high rates of illiteracy and poor infrastructures. Economic growth has not been uniform across all states and regions. Technological and corporate hubs like Delhi, Bangalore and Mumbai have attracted the maximum skilled and mobile workers leading to excessive urbanization and congestion, whereas other cities and rural areas have been lagging in employment generation and skill formation. Given the success of ICT in India, a key issue is how the ICT sector performs in terms of employment and wages. This book sheds light on the substantial job creation by the Indian ICT industries, but also the challenges ahead related to the fact that rapid technological changes also lead to higher demand for advanced skills.

For the labour market in India, the very low ratio of female-to-male labour force participation rate in India is also a serious concern. Especially in comparison with China and Brazil, gender inequality patterns show that women do not play yet a 


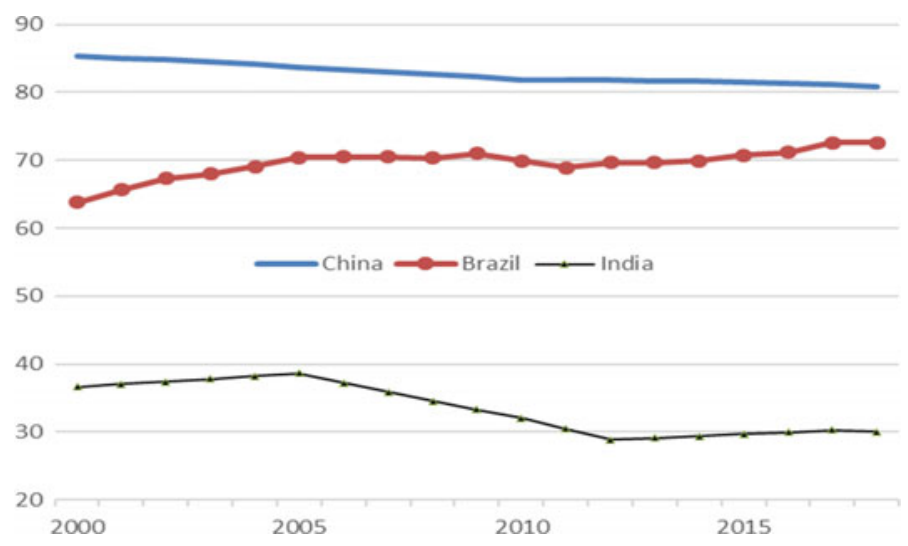

Fig. 2 Ratio of female-to-male labour force participation rate 2000-2018 (\%, ILO estimate). Source World Development Indicators, World Bank

substantial role in the labour force as compared to men, and the ratio of female-tomale participation has even been declining (see Fig. 2). This can be taken to be a sign of low human progress in India despite healthy growth figures.

Increased female labour participation represents a significant development potential not only at the individual level but also for India as a whole, by tapping the huge unexploited potential among women. In the book, we also address how ICTs affect the labour participation of women.

Inequality pervades India not just at a geographical level, but also at an individual level. The remarkable economic growth has only to a limited extent been able to narrow the gap between the haves and the have-nots, as many of India's poor are yet to receive the fruits of India's economic growth. According to a recent report by Oxfam (cited in Business Today 2019, 30th January), India's richest 1\% held $58 \%$ of the country's total wealth, which was higher than the global figure of about $50 \%$. The wealth of this elite group increased by over about 293 billion USD (or, Rs. 20.9 lakh crore) during the period under review - an amount close to the total expenditure estimated in the Union Budget 2017. India's top 1\% of the population now holds $73 \%$ of the wealth, while 67 crore citizens, comprising the country's poorest half, saw their wealth rise by just $1 \%$. So, India's economic growth has not been pro-poor, and trickle-down economics has not played its role as expected. Hence, taking into account India's current position, it can be said that inequality is harming not only individuals but also adversely affect growth prospects and overall welfare. How do ICTs affect this pattern? This book sheds light on the exponential spread of ICT in India, partly also among the poor. Furthermore, ICTs are applied in public policies related to poverty, and some chapters address how these affect socio-economic outcomes and inequalities within the country.

India has also been plagued by corruption and a lack of transparency in institutions. One indicator of this is its score in the Corruption Perception Index. According to the World Governance Indicators, compiled by the World Bank, the figures on the 
control of corruption show a general improvement in both India and China in recent years, while Brazil shows opposite trend (Fig. 3). Still, corruption levels in China and India score well below the average. This has led to inefficient institutions that are unable to benefit the people to their full potential and are hampering India's image as a lucrative place for business. In turn, this has also affected economic activity and employment generation in India, again reinforcing inequality. Corruption also manifests itself as development fees, particularly when funds allocated to various social welfare and developmental programmes such as those earmarked for building roads/schools/expanding infrastructure for public distribution system (PDS) in villages are misused. There is ample anecdotal evidence to show how corruption in the PDS system leads to grains not reaching the actual beneficiaries due to leakages. There has been much debate and discussion on how these issues can be resolved, and one remedy that has found some support is to replace transfers in kind by transfers in cash. This is possible and plausible only when there are well-developed digital channels capable of transferring money to bank accounts seamlessly, thus stressing the importance of ICT for development and welfare enhancement. Has ICT effectively reduced corruption in India? Two chapters of this book investigate specifically this issue.

Moreover, India has not performed at satisfactory levels when it comes to life expectancy as compared to China and Brazil, two economies that are good comparison points as far as economic development and growth are concerned (see Fig. 4). Even though life expectancy at birth has increased, India is still lagging behind China and Brazil. It is hence relevant to ask whether India has succeeded in using ICT effi-

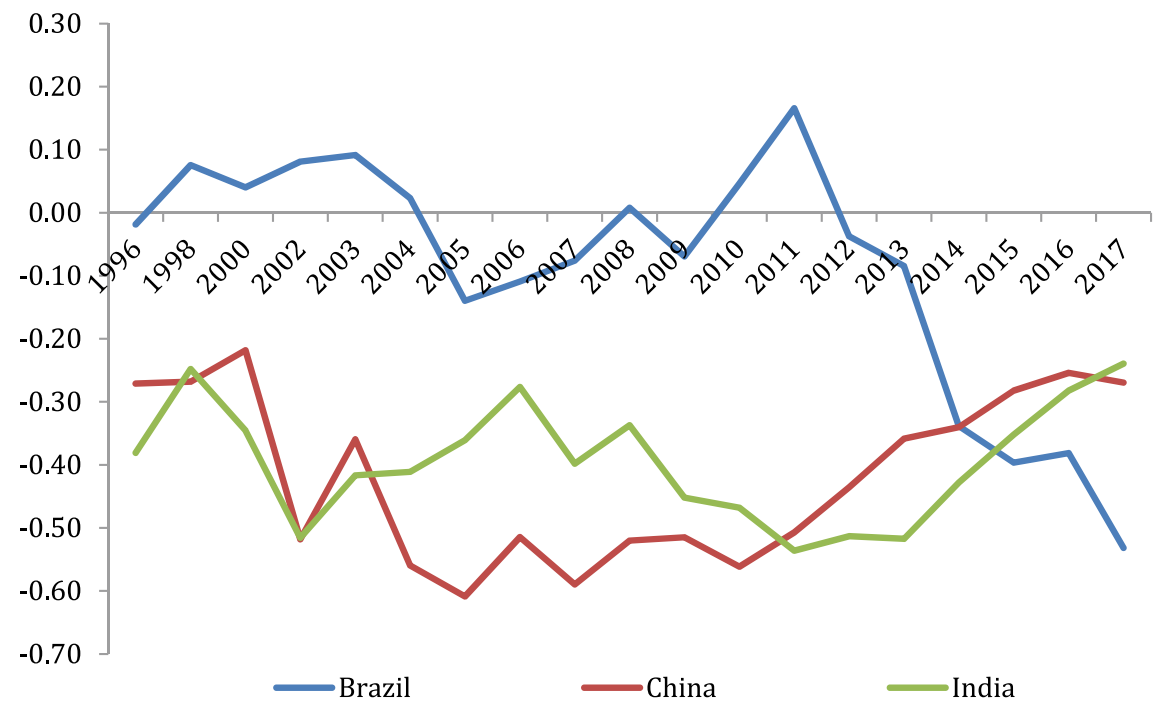

Fig. 3 Control of corruption index in major developing countries: 1996-2017. Source Wold Governance Indicators, World Bank 


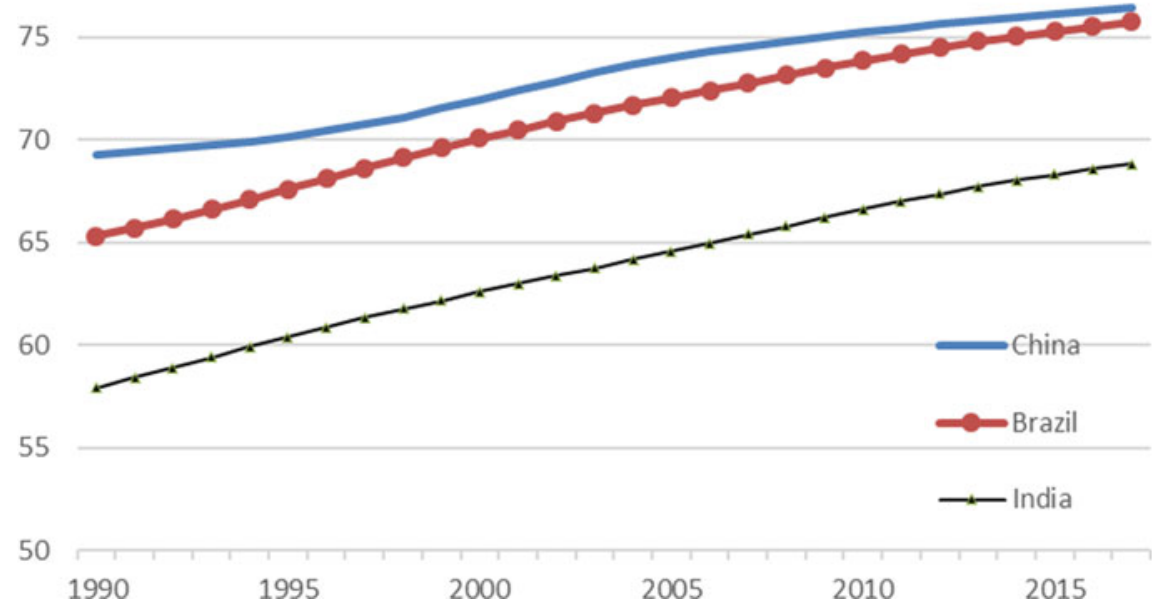

Fig. 4 Life expectancy at birth in India, China and Brazil, 1990-2016 (number of years). Source World Development Indicators, World Bank

ciently in order to provide better health services and governance to the benefits of its large population.

Therefore, it is evident that in spite of the spectacular growth experienced during the last two decades, the related benefits have not percolated to every section of the society in India. The majority of workers are engaged in the informal sector, there are less for formal jobs with growing the formal sector, inequality has increased sharply even though poverty has reduced to some extent, the rural sector is lagging behind, corruption and inefficiencies are crippling the public delivery of welfare programmes and so on. These have been perennial problems of the Indian economy since independence and thereby have remained binding constraints.

Aware of these problems, public authorities and policy makers have recently pointed to digitalization of the economy as an important strategy to address the twin challenges of economic growth and social inclusion. The implicit understanding is that a faster pace of adoption of ICTs will enhance productivity and economic efficiency, bring greater transparency in the delivery of public services and welfare programmes, reduce the level of corruption, integrate remote places with cities and towns and improve the level of democratic participation.

However, as noted in Sect. 1 above, research on digitalization and development points out that socio-economic benefits of ICT adoption are far from being automatic and do often depend on a set of economic, social and institutional dimensions that characterize each national economy. Hence, it is relevant to ask whether digitalization will be the right strategy to foster socio-economic development in India in the coming years, and what complementary factors and capabilities the Indian economy will have to focus on in order to magnify the benefits of ICTs and limit the related 
risks. This book focuses on three major themes that are crucial to address the question of digitalization and development in India: (1) economic impacts of ICTs; (2) digitalization and inequalities; (3) governance and users' well-being.

\section{Digitalization and Development in India: Patterns and Questions}

The ICT sector has been expanding rapidly in the last few years all over the world, as evident from its share of GDP and contribution to GDP capital (Fig. 5).

According to a recent report by the International Telecommunication Union, over 3 billion people are now online and ICT growth is buoyant across all countries. Latest data show that Internet use continues to grow steadily, at $6.6 \%$ globally in $2014(3.3 \%$ in developed countries, $8.7 \%$ in the developing world). The number of Internet users in developing countries has doubled in five years (2009-2014), with two-thirds of all people online now living in the developing world.

More than $80 \%$ of the youth populations are online in 104 countries. In developed countries, 94\% of young people aged 15-24 use the Internet compared with $67 \%$ in developing countries and only 30\% in Least Developed Countries (LDCs). Out of the 830 million young people who are online, 320 million (39\%) are in China and India (Fig. 6). Nearly 9 out of 10 young individuals not using the Internet live in Africa or Asia and the Pacific. This emphasizes the importance of ICT and the role it can play in affecting economic outcomes.

A report on the new digital economy and development, compiled by UNCTAD (2017), notes that it is not straightforward to measure the impact of ICT growth on development due to its rapidly changing nature and a complex web of areas

(a) Share in GDP, OECD countries, 2011

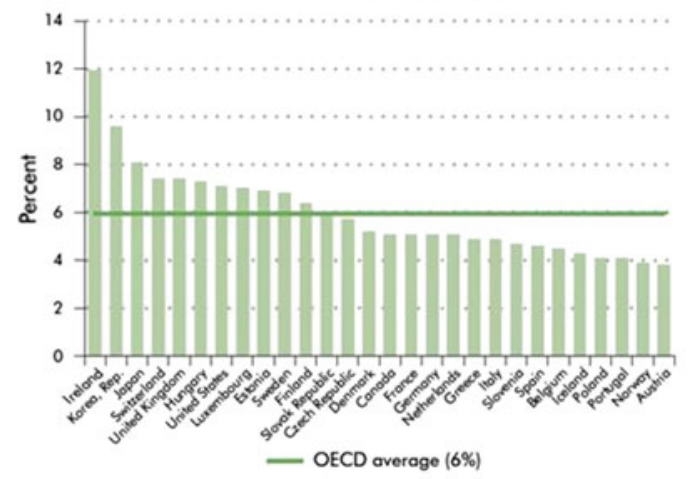

(b) Contribution to GDP growth, 1995-2014

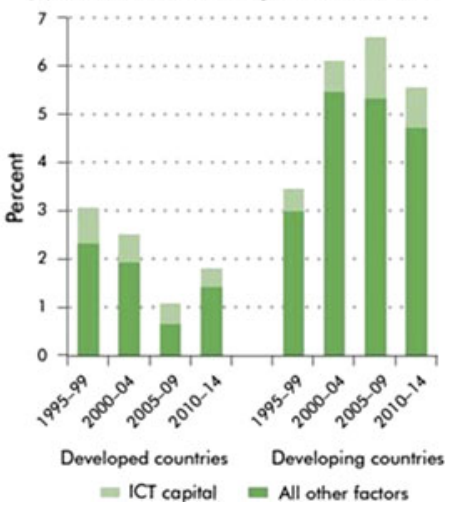

Fig. 5 ICT Sector as a share of GDP and contribution to GDP growth. Source ICT-centric economic growth, innovation and job creation, ITU 


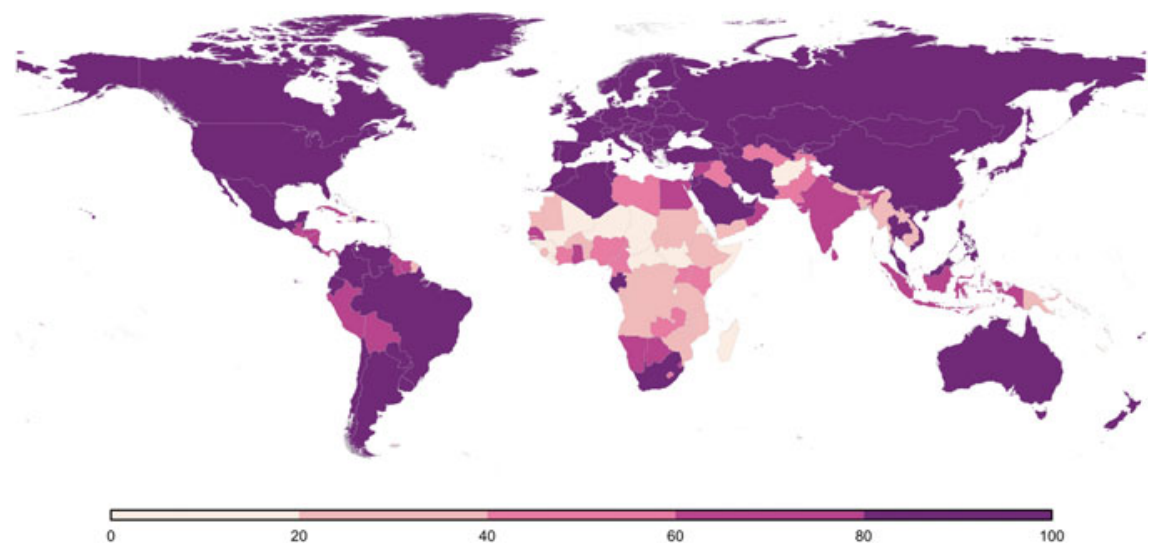

Fig. 6 Proportion of youth (15-24) using the Internet (2017*). Source International Telecommunications Union (ITU). Note *Estimates

that are impacted by growth in the ICT sector. Nonetheless, the study considers a diverse range of impact areas such as economic performance, employment, innovation (including research and development), privacy and security, education, health, citizen participation, individuals and communities and the environment. The book will focus on the following three related themes.

\subsection{ICTs and Economic Performance}

The exposure to ICT raises efficiency and productivity, saves time, reduces hardship, eliminates information distortions, improves communication and more so (Oulton 2012; Castellacci and Tveito 2018). As a result, ICT adoption has positively impacted on economic outcomes, like capital formation, exports and government accounts. The impact of ICTs has been viewed as a driving factor contributing to the GDP of an economy by raising the level of TFP and labour productivity. Crafts (2004) argued that the impact of ICTs on labour productivity in modern society has been greater than that of the steam engine appeared in the mid-nineteenth century. The maximal impact of this technology on labour productivity was $0.41 \%$ per year during 1850 70 , whereas the estimated effect of ICTs on US labour productivity growth over 1974-90 was $0.68 \%$ per year.

A recent report by OECD (2018) focuses on fostering growth through digitization in South-east Asia, China and India. It indicates that ICT services embodied in manufacturing and services account for a considerable share of the value of exports from these Asian nations. According to a report by the World Bank Development Research Group, the Better Than Cash Alliance and the Bill \& Melinda Gates Foundation to the G20 Global Partnership for Financial Inclusion, digitizing payments and remittances are vital to achieving G20 Goals, contributing to its core goal of achiev- 
ing strong, sustainable and balanced growth. The report shows how the widespread adoption of digital payments in all their forms, including international and domestic remittances, can be instrumental in reaching the goals of G20. Digitization can help overcome the costs and physical barriers that have harmed valuable financial inclusion efforts, offer the opportunity to rapidly scale up access to financial services and promote women's economic empowerment by facilitating greater account ownership and asset accumulation.

Promoting digitalization has been the Indian government's focus for many years now. This includes attempts made to provide most services to every citizen on their web portals or electronically and make the transactions transparent and smooth. The Indian government launched the revolutionary reform "Digital India" in 2015, under which it envisioned increased Internet connectivity and making India a digitally empowered nation. This was also seen as being an engine propelling the growth of businesses, employment generation and increasing transparency in major sectors of the economy. Increased Internet penetration, improved telecom services, availability of skilled IT workers, start-ups providing ICT services and the government encouraging ICT through various schemes, operations and services are important factors fostering economic performance.

Access to ICT products by Indian citizens has grown substantially (Fig. 7). Internet, landline and mobile telephones are the major three types of products that are commonly used. Mobile use accelerated since early 2000s. However, in contrast to the growth of mobile/wireless telephone, the growth in usage of landline telephone has been falling for the same period. While mobile telephone subscribers register a substantial increase to 87.3 per 100 persons, landline connections drop from around 5 per persons in 2006 to 1.7 per 100 persons in 2017. The growth in the Internet and broadband connections has been modest. The growth of Internet subscribers has

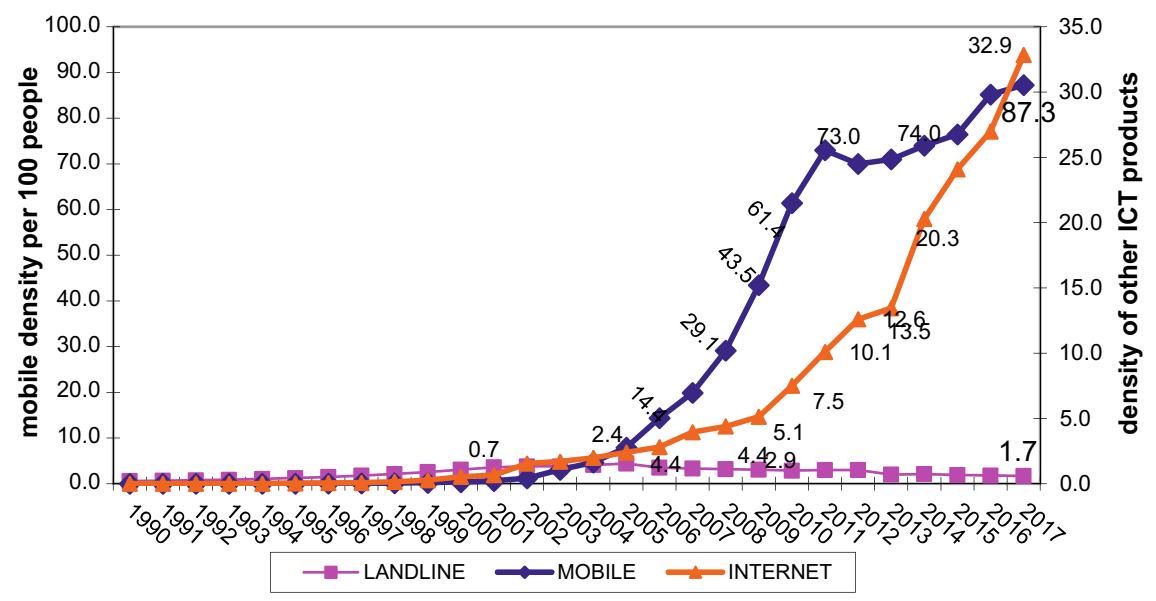

Fig. 7 Density of ICT products (per 100 persons) in India, 1990-2017. Source Mohanty (2019) and Annual Report, Telecom Authority of India (2018) 
been slightly better since 1999 . The density of Internet users reached 32.9 per 100 persons in 2017 from 4 per 100 persons in 2007, eight-time rise in the last ten years.

An even more recent trend relates to increasing patterns of automation, and the effects this may have by affecting labour wages and employment in developing economies. Further, digital communication technologies may also affect economic outcomes by enhancing business firms' productivity and their ability to participate in international trade. However, while these recent patterns foster expectations of strong economic benefits for developing economies, extant research has not yet provided analyses and evidence to corroborate these optimistic expectations. Have recent digitalization patterns experienced by the Indian business sector fostered economic growth, employment and international competitiveness of the Indian economy?

\subsection{Digital Divide and Inequalities}

Despite the government's efforts towards increasing ICT goods and services in the economy, there is a clear digital divide in the nation, as shown by data from the ICE $360^{\circ}$ survey (2016), which gives insights into economic and social well-being of households, provides normative measures of social, political and financial inclusion and a degree of access to public goods, infrastructure and welfare measures.

A survey conducted by the People's Research on Indian Economy (PRICE 2016), covering 60,360 households and studying digital networking by deep diving into the Internet usage, its patterns, mode and purpose of their access, reveals that 10\% (27 million) households reported having an Internet connection at their home. But, there were 22\% (62 million) of Indian households where at least one member was accessing the Internet (either at work or home or elsewhere and either through a computer or mobile). It also showed that while every tenth underdeveloped rural householdincluding those in districts such as Kalahandi (Odisha) and Bastar (Chhattisgarh) has access to the Internet, in the metros every second household has Internet access, hence giving evidence of the rural-urban differences in access to ICT goods. Additionally, the survey results showed that the level of education and Internet access are highly correlated since every second graduate household has at least one member who accesses the Internet versus every hundredth in the case of an illiterate household. The digital divide becomes more palpable between the rich and poor. Nearly $47 \%$ of rich households (top quintile) have at least one member with access to the Internet in contrast to only $4 \%$ of poor households (bottom quintile). This shows that even though efforts have been made to increase Internet connectivity by the Government in India, the impact has not been uniform across all sections of society.

In addition to Internet connectivity, the government has also made efforts towards increasing mobile connectivity, as mobile phones can be important tools especially in poorer areas where Internet use is not as widespread. However, a gap in the provision and use of ICT goods and services is visible even in terms of mobile phones. The 2017 global survey by the Pew Research Center shows that only one in four Indian adults report using the Internet or owning a smartphone. Despite the booming 
Percentage of Adults (18+) who use the Internet at least occassionally

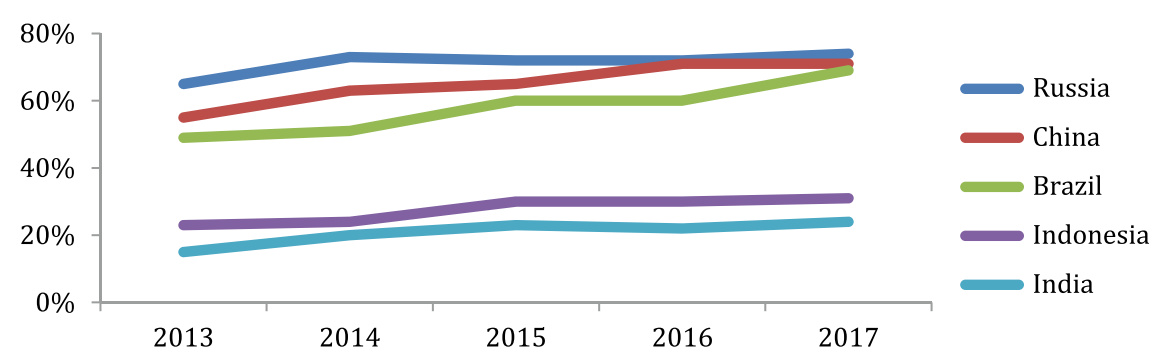

Fig. 8 Internet use in BRICs countries. Source Poushter et al. (2018)

economy, India's progress in smartphone penetration has been slow. In 12 of the 22 emerging and developing nations surveyed, fewer than $50 \%$ report owning a smartphone, and in India and Tanzania, less than one-quarter report owning smartphones, the lowest among the countries surveyed. This slow adoption of smartphones in India has hampered the growth of the Internet in the country since most Indians tend to access the Internet on their mobiles. In addition to the rural-urban, rich-poor and regional digital divide, India is also lagging in Internet usage (see Fig. 8) when a comparison is made with other emerging economies, as shown by the Poushter et al. (2018).

To bridge the digital divide, the central government has disbursed Rs. 34,000 crore to lay high-speed Internet in 150,000 villages by 2019 , but only about 70,000 villages have been covered until now.

Even though there has been a major increase in the use of ICTs, this has not been uniform among genders. As Fig. 9 shows, the digital gender gap persists, as the proportion of men using the Internet is higher than the proportion of women using the Internet in two-thirds of the countries worldwide. The proportion of women using the Internet is $12 \%$ lower than the proportion of men using the Internet worldwide. While the gender gap has narrowed in most regions since 2013, it has widened in Africa. In Africa, the proportion of women using the Internet is $25 \%$ lower than the proportion of men using the Internet. In LDCs, only one out of seven women is using the Internet compared with one out of five men.

More than $70 \%$ population still live in rural India. There is increasing concern that the access to ICT is rising at much slower rate than that of urban area leading to a rising digital divide between urban-rural areas in India. Tele-density, which denotes the number of telephones per 100 populations, is an important indicator of telecom penetration in a country. Tele-density in India, which was $10.37 \%$ in 2001, sharply increased to $167.17 \%$ at the end of 2012 in the urban areas, followed by a decline to $154.18 \%$ in 2016 (Fig. 10). However, the tele-density was $0.93 \%$ in 2001 in rural areas, and this shows much lower than the urban share. But, the share has gradually raised to $51.26 \%$. The gap of tele-density has increased ten times during the period, and this shows an increased digital divide in India. 


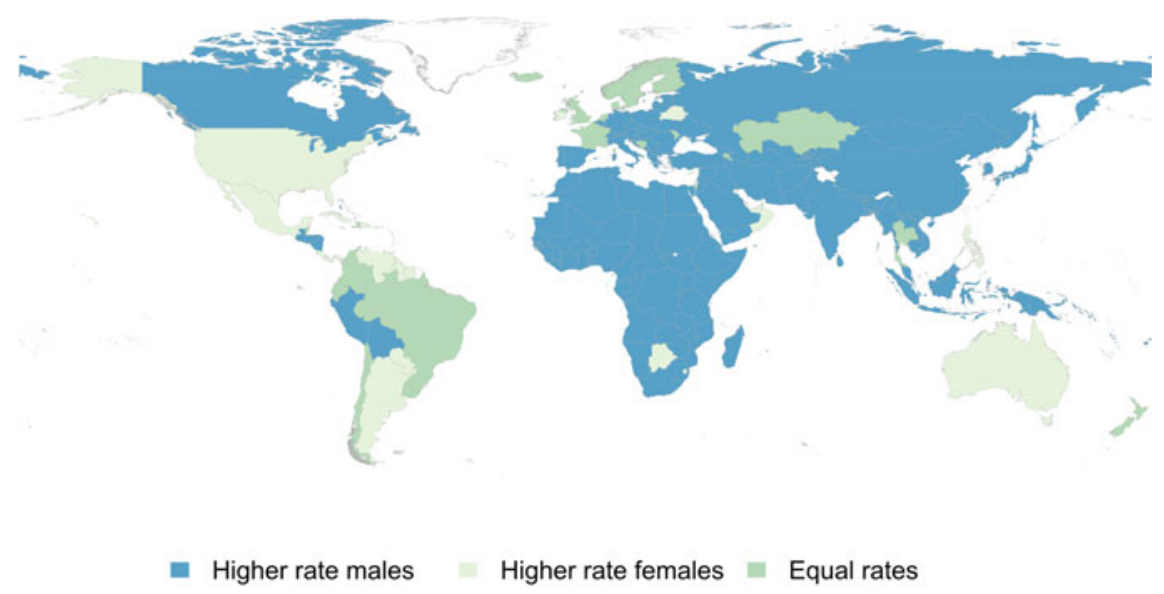

Fig. 9 Proportion of Individuals using the Internet, by gender $(2017 *)$. Note * Estimates. Proportions in this chart refer to the number of women/men using the Internet, as a percentage of the respective total female/male population

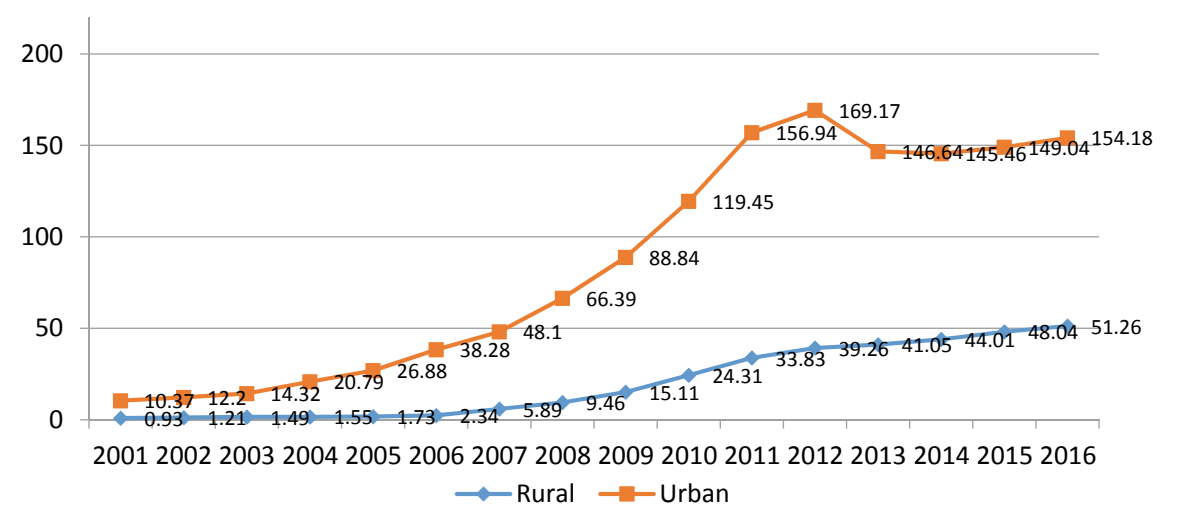

Fig. 10 Trends in tele-density in India during 2001-2016 (number per 100 populations). Source Annual Reports, Telecom Authority of India, 2018

Another current concern that will become increasingly important in coming years is that digitalization and automation of tasks may increase the skill gap in the labour market, and hence exacerbate wage and occupational differences between skilled and unskilled workers (Acemoglu and Restrepo 2018; Brambilla and Tortarolo 2018). Hence, there is the risk that increased firms' productivity enabled by ICTs will go hand in hand with an increasing skill gap and inequalities in the labour market, which is an issue of serious concern for a large population country such as India. On the whole, current digital divide patterns make it relevant to ask to what extent India will be able to close these divides in the coming years, and what the effects of these inequalities will be for Indian households and consumption patterns. 


\subsection{ICTs, Governance and Users' Well-Being}

The impacts of ICTs on welfare go, however, much beyond than their effects on economic growth and income inequalities. ICT users and citizens can be affected in a number of ways by the increasing use of digital technologies. In particular, the socio-institutional environment that characterizes our society, such as governance structures, trust in other citizens, safety and security, is highly relevant for wellbeing (Dolan et al. 2008). ${ }^{3}$ Helliwell (2006) point out that the ability of governments to provide a trustworthy environment is paramount for well-being, particularly in those countries with poor governance and low absolute income. Internet applications that improve in some way the socio-institutional environment can positively affect citizens' welfare. Therefore, if governments are committed to providing more online public services, this will likely increase well-being too.

There are three distinct channels mechanisms that are relevant here (Castellacci and Tveito 2018). First, moving certain public services online can save citizens' time and diminish the effort previously allocated to monotonous (and sometimes stressful) tasks. Second, through increased access to information, individuals can have better information about their society, increasing their sense of belonging to their community as well as their safety. For example, in India, citizens can register where they have been asked to bribe governmental officers, and their reports are sent to government officials and the media to increase transparency and the quality of life among citizens, who can learn where to go to avoid having to bribe someone (Ramanna and Tahilyani 2012). This can decrease the spread of bribery and corruption, increase trust and thus spur well-being. Third, digital communication tools enable more rapid and transparent interactions between citizens and public authorities, through, e.g. online portals for e-government services, or by improving civic engagement among citizens.

In the Indian context, the issue of arguably highest relevance is how ICTs can contribute to limit the extent of corruption and improve the country's governance quality. Existence of a parallel economy that thrives and flourishes on cash-based businesses and entities can be undermined through digitalization. Most of the individuals running the parallel economy do not have proper bank accounts and avoid paying taxes to the government. Digitalization initiatives like taxation being brought online and steps like demonetization can aid the government to weed out corruption from our system. If administered and implemented correctly and efficiently, these can be major game-changers. ICTs are supposed to help reduce the activities falling within the ambit of the informal sector and hence increase growth and development in India, which is why there has been a growing focus on these by the Indian government in the recent years.

An interesting example is the Aadhaar system, the world's most ambitious digital identity programme, which is becoming increasingly necessary for financial transactions and access to social welfare. The Aadhaar system has, however, also led to increased opportunities for corruption. Evidence from an arid village in Jharkhand

\footnotetext{
${ }^{3}$ These introductory paragraphs of Sect. 3.3 are based upon Castellacci and Tveito (2018).
} 
shows the misery of families who were deprived of subsidized food from the vast public distribution system because their ration cards had not been linked to their biometric-based 12-digit personal identification numbers. Villagers travelling to the nearest town to submit the forms and papers necessary to get their ration cards linked to Aadhaar either had to shell out days of family earnings to bribe the government officers at the office or face rejection and the risk of having no food for many more days of the month.

Even though the government had made the linkage mandatory in order to avoid leakages and digitalize the process, it can be seen that a lot of people actually faced more hardships in getting access to food, hence hampering their well-being despite a well-functioning digital set-up. Similar issues have been faced by pensioners who are unable to get their pensions linked to Aadhaar. Many had to pay bribes to be eligible to receive their pensions and many genuine pensioners were excluded when 300,000 "fake" pensioners were removed from the list of beneficiaries (Biswas 2018). This happened due to mistakes made by data operators, resulting in discrepancies in name and age, highlighting the dangers of merely relying on the provision of ICT goods and services without ensuring a supporting institutional system to minimize risks associated with their provision.

These dangerous avenues that the increasing use of ICT has opened up need much more attention by policy makers. Various attempts have been made by the government to reduce informality and corruption through the adoption of ICT in its operations. But despite the many measures taken by the government to clean the system, India's ranking in the global Corruption Perceptions Index, released by Transparency International, slipped two places to the 81st mark in 2017 (Transparency International 2017). The report also termed India as one of the "worst offenders" in the AsiaPacific region in terms of corruption and press freedom, attributes that are indicators of well-being. In 2016, it was ranked 79 among 176 countries in the index. In 2017, India's ranking stood at 81 with a score of 40 among 180 countries.

All the above evidences point towards weak institutions that are limiting otherwise positive prospects for the people. There is a dire need to shift the focus from a mere increase in the use of ICT goods and services to strengthening India's governance and institutional set-ups, to make them strong enough to provide the requisite support for ICT to affect well-being through the channels mentioned in extant research. Without the supporting background of a strong institutional framework, the evils of corruption, informality and mismanagement shall continue to negatively affect growth and well-being and prevent the positive effects of ICT from percolating to the whole economy.

\section{This Book: Themes and Contributions}

The present book is centred on the three major themes and questions outlined in the previous section. The book is therefore organized in three parts, one focusing on ICTs and economic outcomes, the second on digital divides and inequalities and 
the third on governance and users' well-being. The book collects on the whole 15 studies that present fresh empirical evidence and analyses on the issues raised earlier in this chapter. Before presenting these empirical contributions, though, the book includes a comprehensive survey of relevant literature on ICTs, economic growth and well-being.

Chapter "ICT, Growth and Happiness" (Maurseth) surveys extant research on ICT, growth and development in a cross-country comparative perspective. According to Maurseth, the diffusion of ICT typically follows an S-shaped development over time. This is also reflected in the sharply falling prices of computer equipment, where the so-called Moore's law-i.e. that real price for computers halves every 18 months - has been largely supported. According to Gordon (2016), the improvement in the performance/price ratio is unprecedented in history. The impact of ICT should also be enhanced by its nature as a general-purpose technology with widespread application, the public goods nature of some of its infrastructure (especially the Internet), and the special nature of digital products, that are often non-rival in the sense that they can be accessed by many users without affecting the utility of the others.

Given the fundamental impacts of the ICT revolution and its pervasive and observed impacts, we would expect ICT to be heavily reflected also in the statistics on growth and development. In this light, we expect that the diffusion of ICTs should have a clear impact on growth and productivity. In the light of existing research, however, this is surprisingly unclear. According to Chapter "ICT, Growth and Happiness", the macro-impact of ICT on productivity and economic growth is mixed, with an overall modest effect of ICT on growth so far. The spread of ICTs coincided with lower growth rates in industrial countries from the 1970s. Hence, the famous paradox of Solow (1987): "You can see the computer age everywhere but in the productivity statistics". Higher growth rates in the 1990s contributed to renewed optimism, but the positive impact of ICT was more visible in the USA than in Europe and Japan, and slower growth after the 1990s dampened the ICT optimism. Results from studies using macro-data are therefore mixed and divergent, some suggesting a positive impact of ICT on growth, others not. Adding new results from growth regressions, Chapter "ICT, Growth and Happiness" finds that the impact of Internet use on economic growth was positive before the year 2000, but for rich countries after 2000, the effect was even negative.

For development, a key issue is whether ICTs promote convergence and inequalities among countries. If high skill levels and sophisticated infrastructure are required to benefit from ICTs, rich countries may benefit more from ICTs so there may be economic divergence and a growing digital divide. On the other hand, if ICTs are non-rival and accessible for all with low thresholds, or if poor countries may "leapfrog" and drop expensive intermediate steps such as fixed telephone lines, the outcomes may be digital and economic convergence. According to Chapter "ICT, Growth and Happiness", results are also mixed in this respect. Some contributions find convergence, others divergence. According to Yousefi (2011), the observed growth impact of ICT is stronger for middle-income and rich countries, and several studies point to the 
importance of complementary assets such as literacy and education that are crucial for the "absorptive capacity" of countries with respect to ICT. Adding own results, Chapter "ICT, Growth and Happiness" lands on the positive side: while the Internet had a negative impact on growth in rich countries post-2000, there was a persistent positive effect in poor countries.

In the light of the diverging evidence based on macro-data, it is perhaps a consolation that studies at the firm level provide a more optimistic view, with stronger productivity effects of ICT. Chapter "ICT, Growth and Happiness" points out that firms that use ICT have higher growth in productivity than other firms and growth rates are often high in ICT producing industries. Some studies indicate that the direction of causality is an issue: ICT may enhance productivity and growth at the firm level, but ICT use may be endogenous so the causality may also run in the opposite direction.

For India, an important issue is also how ICTs relate to sectoral growth patterns. The so-called Baumol's disease predicts that ICTs are initially progressive but in the longer run related to stagnant industries or services sectors. In the light of India's services-driven growth, the long-run growth potential of services is a key issue. According to the survey in Chapter "ICT, Growth and Happiness", some contributions conclude that Baumol's disease has been cured, but others have found a higher growth potential on some manufacturing sectors than in services.

A reason behind the conflicting evidence on the impact of ICT may also be problems of measurement. ICTs are changing technologies and products so that standard metrics fail: counting the number of computers will not capture the immense change in their performance. These measurement problems apply to production as well as consumption and may be particularly important for ICT products. For consumption, an issue is how to measure well-being: do ICTs affect well-being beyond what can be captured by standard metrics such as income or income per capita? Chapter "ICT, Growth and Happiness" also surveys the literature on how ICTs affect measures of subjective well-being (Castellacci and Tveito 2018). Also here, there could be opposing forces at work. The Internet may be used for welfare-enhancing information and social interaction, but also create addiction and isolation for its users. There is generally a positive and logarithmic relationship between income levels and subjective well-being; hence, ICT may impact well-being indirectly via income. There is a fast-growing body of research based on person-level data, and the survey of recent contributions in Chapter "ICT, Growth and Happiness" indicates a mainly positive effect of ICTs on subjective well-being, however varying with individual or group characteristics such as age. There may also be saturation effects, by which ICT access is positive but with diminishing marginal returns, and even negative effects according to some studies.

\section{Part I: ICTs and Economic Performance}

In the light of the considerable measurement problems related to ICT, it is pertinent that Part I of the book, on ICTs and economic performance, starts with a chapter contributing significantly to the measurement of ICT effects in India. In the existing literature on ICT and growth, many empirical studies have relied on data for rich 
countries, and for the study of ICT and development, it is urgent to provide better data for developing country use of ICT. Chapter "ICT Investment and Economic Growth in India: An Industry Perspective" (Erumban and Das) maintains that the lack of accurate data on ICT use by industries is a major reason why knowledge on the impact of ICT on growth in India is still limited. Using various data sources and overcoming hurdles related to data availability, consistency and measurement, the authors estimate aggregate and sector-level ICT investments in India over time. This reveals that ICT investments have increased, but their share of GDP has declined, and India lags behind the more mature economies. The authors then extend the India KLEMS database to include ICT capital. KLEMS (capital-labour-energy-materialsservices) is an international database built for the analysis of growth and sectorlevel productivity, with data that are comparable across countries. Using the new data, the authors find that the contribution from ICT investment to growth in India has increased marginally, but the manufacturing sectors lag behind the aggregate economy. The chapter suggests that complementary assets such as skill levels may explain this lag.

India is currently the largest exporter in the world of ICT-related services, but the industry is in constant change. According to Chapter "Technological Disruptions and the Indian IT Industry: Employment Concerns and Beyond" (Sagara and Das), the information technology (IT) industry in India currently employs 3.8 million people and contributes more than $9 \%$ to Indian GDP. Key segments of this industry are IT services and business process outsourcing (BPM), and the authors show that employment growth in these segments is strongly export-driven. A key issue in the chapter is how India will cope with the "Fourth Industrial Revolution"-including developments such as cloud computing, big data, Internet of things (IoTs), robotics and more. Based on a variety of sources, the chapter maps developments and industry perceptions in different technological fields and concludes there is a threat of technological disruption to the Indian IT industry. The change is likely to require considerable re-skilling and up-skilling in the industry, and the authors argue that a paradigm shift is needed for the industry to move up the value chain and maintain its leading role. The new developments represent opportunities as well as challenges. Innovation, improving IT infrastructure and removing legal and administrative bottlenecks are needed if the Indian IT sector is to sustain its leadership.

For ICT and development, a key issue is the speed of technology diffusion, as also addressed in Chapter "ICT, Growth and Happiness". In Chapter "IT Enabling Indian Firms: The Importance of IT Outsourcing Companies" (Kite), the role of information technology outsourcing (ITO) for technology diffusion is addressed. While previous literature has examined the role of ITO from rich countries, Kite presents new evidence based on a large data set for Indian firms, including their use of ITO. Kite finds that there is a strong positive impact of IT outsourcing on output and productivity and that the effect is bigger than the one achieved by IT investments alone. The analysis therefore also relates to Chapter "ICT Investment and Economic Growth in India: An Industry Perspective": IT investments are not enough-they have to be complemented by other assets such as skills, and ITO is one way for Indian firms to acquire these complementary assets. In addition to this evidence 
from a large firm-level data set, Chapter "IT Enabling Indian Firms: The Importance of IT Outsourcing Companies also presents qualitative evidence from interviews on the institutional characteristics of ITO. This evidence suggests that ITO companies are engaging in a conscious process of learning, and thereby facilitate technology diffusion into India, also by adapting foreign innovations to the local context.

ICT is not only transforming production and consumption, but also the networks and communication between producers, traders and consumers. ICT is thereby changing the world economy by reducing information and communication costs across borders. This is strongly evident in the evolution of global value chains, including business outsourcing and technology diffusion. Three other book chapters examine how ICT facilitates trade, internationally but also within India. According to the optimistic view supported by, e.g. the "flat earth" prediction of Friedman (2005), ICT should lead to the integration of markets and convergence of prices across cities, regions and countries. Also in this area, the research evidence is mixed since the role of distance and borders is persistent and not easily eliminated. Furthermore, there are also situations where low transaction costs promote spatial agglomeration so that spatial inequality may persist in spite of lower transaction costs. Nevertheless, there is growing evidence that ICT actually reduces the impact of borders and distance (see, e.g. Freund and Weinhold 2004; Lendle et al. 2016).

Based on the recent literature on trade with firm heterogeneity (e.g. Melitz 2003), ICTs could affect firms' export decisions by reducing entry barriers in the form of sunk export costs. ICTs could also affect export decisions directly through firm productivity if only the most productive firms export. Chapter "ICT, Access to Finance and Firm Exports: A Cross-Country Study" (Singh and Maiti) suggests that a third channel could potentially be ICTs' impact on access to finance, given that finance is important for covering the fixed costs of exporting. With this point of departure, the authors examine how ICT affects export decisions of individual firms across the world, using data from the World Bank Enterprise Survey. The conclusion is indeed affirmative: ICT is export promoting. Some evidence is also provided to the effect that ICT promotes the access to finance and thereby interacts with ICT in the determination of firm-level export decisions. The latter effect illustrates that ICT interacts with other assets or institutions, from strong complementarity in some cases to a secondary indirect effect as in this case.

With online communication around the clock, a new phenomenon in world trade is time zone trade; e.g. news and stock are monitored and traded around the clock, and when time is scarce, some tasks can be efficiently done by switching production between time zones. Time zone differences can be negative by making synchronization more difficult (when your business partner sleeps), but positive if there is something to gain from round-the-clock operation (named the continuity effect in the literature). Chapter "Time Zone Differences and Service Trade" (Mandal and Prasad) analyses the issue of time zone trade. According to their study, past evidence suggests that the continuity effect is on the whole stronger than the negative synchronization effect. Time zone trade is particularly relevant to India due to her large ICT-related services exports, and the fact that more than half of these exports are directed to the USA and Canada-i.e. several time zones away. In the chapter, 
the authors examine theoretically the potential impact of time zone trade. In their model, time zone trade increases production and the price of the traded services and raises the price of the factor used intensively in their production-and in particular skilled labour.

Focusing on the local level in India, Chapter "Towards One Agricultural Market in India: Does the ICT help?" (Ghosh, Rajeshwor and Vinit) examines whether ICT has led to integrated agricultural markets and reduced price dispersion across Indian regions. The Government of India and the regions have, jointly with producers, made large efforts to facilitate trade by new ICT infrastructure that improves price and market information and facilitates transactions in agricultural markets. The chapter presents a comprehensive overview of measures and institutions established for this purpose in recent years. Some ICT tools are linked to agriculture marketing reforms so an issue is whether markets are affected by market reforms or by ICT. The authors study empirically whether ICT and/or reforms have led to stronger market integration across Indian states. Examining the wholesale markets for pulses, the authors find some but not universal price convergence across states. Price convergence could also be affected by agricultural policies, particularly public procurement, but with the data at hand it is not possible to distinguish between the impact of ICT and the impact of policy measures.

\section{Part II: Digital Divides and Inequalities}

Since ICTs play a pivotal role in stimulating income through various channels, unequal access to ICTs goods and services across the economy may well be one of the factors contributing to rising inequalities. The widening accessibility of ICT goods and services is broadly defined as the digital divide in the literature. Part II of the book investigates whether ICTs contribute to convergence or, on the contrary, lead to a growing digital divide — between countries, regions and individuals within India.

Chapter "Digital Divide: How India and China Stack up" (Tewathia) investigates the pace and pattern of the digital divide in the largest and rapidly growing nations, India and China, using the ICT diffusion index (ICTDI) across regions. This chapter provides a descriptive empirical analysis for country-level comparison of major economic and information and communication technology indicators and their variation across Indian states and Chinese provinces. India is lagging far behind China with respect to all ICT indicators considered. On the one hand, Internet growth has recently been much faster in India than in China. On the other hand, some Indian states such as Kerala, Maharashtra, Karnataka and Tamil Nadu are more digitalised than others like Bihar, Chhattisgarh and Madhya Pradesh. Similarly, in China, the provinces in the eastern region like Beijing, Tianjin, Shanghai and Guangdong show higher ICT diffusion than the rest.

Using household survey data for India, Chapter "Is India Digitally Divided? Identifying the Determinants of ICT Diffusion at the Household level" (Mohanty) further shows that ICT access over time has been uneven. These patterns confirm the rising digital divide in India not only between regions but also across age groups, gender and castes. Using household data, the study uses probit regression and finds that 
caste, size of the household, occupation, marriage and location of the household significantly affect the intensity of use of ICT devices. The role of education is also important. The study also confirms the conclusion that place and inherent network effect, gender, education, age, occupation and caste are the dominant factors shaping ICT diffusion in India. The poor accessibility of ICT goods and services, specifically in rural areas, is the reason for the rising digital divide between rural and urban areas in India. Poor infrastructure and lack of ICTs supply, as well as less education, are the main reasons for the low accessibility in the rural areas. The chapter further emphasizes that not only the literacy rate but also poor writing and speaking skills remain the binding constraints for lower ICT access in the rural India.

Chapter "Effect of ICT on the Performance of Indian States in terms of Human Development Indices" (Neogi) makes a novel attempt to investigate the impacts of public ICT investments on human development across Indian states using data envelope analysis. The components of HDI have been taken as services produced by the state governments while some variables like tax collection of states, population, etc. are considered as inputs of the states. The differences in the capacity of states in utilization of grants and revenue of the states are important determinants in explaining the disparities among the states. Some of the states like Kerala, Maharashtra, Gujarat, Himachal Pradesh and Punjab are much better in term of human development indicators compared to the other states of India. The study outlines a ranking of Indian states in terms of efficiency using non-radial DEA, using as output variables some main socio-economic indicators and as inputs the revenue of the states, central governmental grants, roads and population of the states. A wide variation in the level of human development is observed across the states, and the revenue spending on the ICT sector explains a significant part of the variation. Taken together, the studies included in part II of this book indicate strongly that the digital divide is a key dimension that goes hand in hand with ICT diffusion in India.

\section{Part III: ICTs, Governance and Users' Well-Being}

Part III of the book collects contributions that investigate how ICTs' adoption affects users' well-being and welfare. As noted in Sect. 3, one of the relevant channels through which ICTs shape users' well-being relates to the effects of digital technologies on governance. Digital governance may in fact affect transparency and efficiency of public goods and services for households and citizens, as well as limit the extent of corruption.

Chapter "ICTs and Effectiveness of Governance: A Cross-Country Study" (Agarwal and Maiti) presents a cross-country empirical study of ICT adoption and the effectiveness of governance. The literature on digitalization and governance has until now mostly focused on the potential positive effects that ICT adoption may have on governance: With the ability of information storing and sharing, ICT innovation can improve governance by enriching the governmental information infrastructure, presenting opportunities for better decision making, encouraging pro-active government-citizen interaction and increasing public accountability. At the same time, however, ICTs also lead to potential risks for users such as cyber-crime, loss of privacy, unemployment and digital inequality. These risks put pressure on the ability of 
a state to govern effectively. On the whole, the resultant effect of ICTs on the effectiveness of governance is hard to predict on a priori ground, and it depends on the relative strength of the two forces. The chapter investigates this idea by using crosscountry unbalanced panel data for the period from 1996 to 2017. The econometric results point out that the improvements in ICTs lead to a rise in the effectiveness of governance, but this positive effect largely depends on the efficacy of the judicial system and the rule of law in each country. In short, the presence of a better rule of law strengthens the favourable impacts of ICT on governance.

Chapter "Red Tape, Corruption and ICT" (Bhattacharya and Mukherjee) presents a study of the effects of ICTs on red tape and corruption. The work focuses on the idea that ICTs may reduce the length of red tape, and it analyses the desirability of introduction of ICTs from the stakeholders' perspective. The chapter presents a theoretical model in which the support for such a reform depends on the stakeholders' profile, the nature of the public goods and services, and the initial length of red tape. The main idea of the model is that, although all types of applicants pay speed money in the presence of red tape, it is not that everyone prefers a corrupt regime to an honest regime. The undeserving applicants do not typically complain about a corrupt regime. The deserving applicants, though, complain about corrupt regime in two types of situations: if the proportion of deserving applicants is high enough and if the proportion of deserving applicants is low but the length of the red tape is not long enough. In the presence of too long a red tape, no one complains about corruption. The introduction of ICTs, by shortening the length of red tape, may increase support for a honest regime if the red tape is not long enough and if the gap between the two types of applicants' pay-off is not large enough. The chapter also provides empirical evidence that illustrates the relevance of this model. The empirical analysis using cross-country data shows that ICT increases demand for an honest regime in general, but it reduces the demand for an honest regime and therefore implementation of further ICT reform in countries with longer red tapes. The results may provide an explanation as to why the introduction of ICTs in many high-corruption economies has not been as successful as previously expected.

While the previous two chapters investigate the theme of ICTs and governance in a cross-country international setting, Chapter "Role of Technology in Governance and Development: The Case of e-Uparjan in Madhya Pradesh" (Pradesh and Mishra) studies the same theme by focusing on the case of e-Uparjan in India. The e-Uparjan is a relevant case of digital inclusion and synchronization of activities of stakeholders like farmers, designate procurement agencies, technology providers, financial institutions and state administrative agencies. The chapter adopts a single case study approach to understand the technology-enabled procurement system at the micro-level. Field observations also expand the scope of understanding of the context and potential implications of the procurement system to associated stakeholders. The main idea of the study is that faster and real-time information flows along the decision nodes can plug in fund leakage, reduce transaction costs and mitigate rent-seeking behaviour of actors along the value chain. The chapter argues that adoption of ICTs can thus have potential to streamline procurement operations and secure farmers' pay-off in time-bound manner through direct benefit transfer under the price sup- 
port scheme. The analysis shows that e-Uparjan appears indeed to have improved operational efficiency of collection, warehousing and optimizing transportation network for food grains procurement and distribution. The case of e-Uparjan is relevant because it offers fresh insights on social policy making as network processes that require an adequate understanding of social realities, seamless synchronization of involved stakeholders and aspects of public procurement policies.

As noted earlier in this chapter, India has very low female participation in the labour market, and an important issue is whether ICTs can improve this important social problem. Chapter "ICT, Gender, and the Labor Market: A Cross-Country Analysis" (Valberg) investigates the effects of ICTs on gender inequalities in the labour market. By increasing efficiency and access to information, lowering transaction costs and creating new jobs, ICTs have also changed the way we work. An aspect that has until now received only limited attention is that ICTs may potentially have beneficial effects on the labour market for women, which have traditionally been limited from working because of time and mobility constraints. A few previous studies on this topic have been conducted at the micro-level for selected countries, but few attempts have been made to systematically investigate the relationship between ICTs, female employment and development taking a cross-country international perspective. This chapter investigates whether ICTs have an impact on gender equality in the labour market, and it is among the first to investigate cross-country trends in this pattern. Using panel data analysis for 156 countries for the period 1991-2014, the work shows that ICTs contribute positively by narrowing the gender gap in labour market participation, mainly due to increased female labour force participation. However, the chapter also points out that the impact is lower in developing countries compared to advanced economies, suggesting that the adoption of digital technologies alone may not necessarily be an effective leapfrogging strategy for increasing female labour force participation in developing countries.

The final chapter shifts the focus to channels through which ICT use affects well-being and welfare at the individual level. Chapter "ICTs Exposure and Its Relationship with Academic Self-efficacy and Achievement of Adolescent students: The Field-level Study in India and Fiji" (Mandal) focuses on a topic of high current relevance: ICT use of adolescents and its effects on well-being. Specifically, the chapter focuses on whether and how ICT exposure affects adolescents' learning at school, by carrying out a novel data collection and empirical field-level study in India and Fiji. Nowadays, children and adolescents spend an increasing amount of time using digital devices such as video games, mobiles, computer and Internet, and doing so they often sacrifice learning and extracurricular activity. This may potentially have serious implications not only on their physical and mental health but also on academic aptitude. Extant literature records few studies in this area showing contentious results that encourage further research. The chapter investigates whether time devoted to ICTs adversely affects academic self-efficacy and achievement of adolescent students in two developing countries, India and Fiji. The study developed a structured questionnaire to capture relevant variables such as time spent using digital devices, academic self-efficacy and achievement and then used these variables in a quantitative analysis. A survey collected relevant information for these vari- 
ables from 873 adolescent students of the tenth class from 16 schools selected in rural and urban areas in India and Fiji. Cronbach's alpha test was used as customary to assess the reliability of the instruments to justify the questions; and then principal component analysis (PCA) was employed to construct a suitable index of the socio-psychological variable academic self-efficacy. Statistical analyses (ANOVA and regression methods) were then used to establish various relationships among these variables. The empirical results suggest that ICTs exposure does on average improve academic self-efficacy and achievement of adolescent students. However, this is the case only for moderate exposure times and up to a certain daily limit ( $3 \mathrm{~h}$ per day); on the other hand, higher exposure times result in weaker learning effects at school. The results presented in this chapter contribute to the current important debate about well-being effects of the use of ICTs, and whether adolescents should use digital devices in a more cautious manner.

\section{References}

Abramovitz, M. (1986). Catching-up, forging ahead and falling behind. Journal of Economic History, 46, 385-406.

Abramovitz, M. (1994). The origins of the postwar catch-up and convergence boom. In J. Fagerberg, B. Verspagen, \& N. von Tunzelmann (Eds.), The dynamics of technology, trade and growth. Aldershot: Edward Elgar

Acemoglu, D., \& Restrepo, P. (2018). The race between man and machine: Implications of technology for growth, factor shares, and employment. American Economic Review, 108(6), 1488-1542.

Agarwal, A., \& Maiti, D. (2019). Digitalization and development in India: Myths and realities. In D. Sanyal \& S. Dutta (Eds.), Impact of digital technologies. Delhi: Kunal Publishers.

Biswas, S. (2018, June 27). Aadhaar: Is India's biometric ID scheme hurting the poor? BBC News. Retrieved from https://www.bbc.com/news/world-asia-india-43207964.

Brambilla, I. \& Tortarolo, D. (2018). Investment in ICT, productivity, and labor demand: the case of argentina, Policy Research Working Papers, World Bank Groups, https://doi.org/10.1596/18139450-8325.

Business Today. (2019, January 30). Income inequality gets worse; India's top $1 \%$ bag $73 \%$ of the country's wealth, says Oxfam. Retrieved from https://www.businesstoday.in/current/economypolitics/oxfam-india-wealth-report-income-inequality-richests-poor/story/268541.html.

Castellacci, F. (2006). Innovation, diffusion and catching up in the fifth long wave. Futures, 38(7), 841-863.

Castellacci, F. (2008). Technological Paradigms, regimes and trajectories: Manufacturing and service industries in a new taxonomy of sectoral patterns of innovation. Research Policy, 37(6-7), 978-994.

Castellacci, F. (2011). Closing the technology gap? Review of Development Economics, 15(1),180197.

Castellacci, F., \& Tveito, V. (2018). Internet use and well-being: A survey and a theoretical framework. Research Policy, 47(1) 308-325.

Crafts, N. (2004). Steam as a general purpose technology: A growth accounting perspective. The Economic Journal, 114(495), 338-351.

Dalum, B., Freeman, C., Simonetti, R., Von Tunzelmann, N., \& Verspagen, B. (1999). Europe and the information and communication technologies revolution. In J. Fagerberg, P. Guerrieri, \& B. Verspagen (Eds.), The economic challenge for Europe: Adapting to innovation-based growth. Cheltenham: Edward Elgar. 
Dolan, P., Peasgood, T., \& White, M. (2008). Do we really know what makes us happy? A review of the economic literature on the factors associated with subjective well-being. Journal of Economic Psychology, 29(1), 94-122.

Dosi, G. (1988). Sources, procedures, and microeconomic effects of innovation. Journal of Economic Literature, XXVI, 1120-1171.

Fagerberg, J., \& Verspagen, B. (2002). Technology-gaps, innovation-diffusion and transformation: an evolutionary interpretation. Research Policy, 31, 1291-1304.

Fagerberg, J., \& Godinho, M. M. (2005). Innovation and catching-up. In J. Fagerberg, D. C. Mowery, \& R. R. Nelson (Eds.), The Oxford handbook of innovation. Oxford: Oxford University Press.

Freeman, C., Clark, J., \& Soete, L. (1982). Unemployment and technical innovation. London: Pinter.

Freeman, C., \& Louça, F. (2001). As time goes by: From the Industrial Revolutions to the Information Revolution. Oxford: Oxford University Press.

Freund, C. L., \& Weinhold, D. (2004). The effect of the Internet on international trade. Journal of International Economics, 62(1), 171-189.

Friedman, T. (2005). The world is flat. A brief history of the globalized world in the 21st century. Ferrar, Strauss and Giroux.

Gordon, R. J. (2016). The rise and fall of american growth: The U.S. standard of living since the civil war. Princeton: University Press.

Helliwell, J. F. (2006). Well-being, social capital and public policy: What's New? The Economic Journal, 116(510), C34-C45.

Lendle, A., Olarreaga, M., Schropp, S., \& Vézina, P. (2016). There goes gravity: eBay and the death of distance. The Economic Journal, 126(591), 406-441.

Melitz, M. J. (2003). The impact of trade on intra-industry reallocations and aggregate industry productivity. Econometrica, 71(6), 1695-1725.

Mohanty, P. (2019). Is India digitally divided? identifying the determinants of ICT diffusion at the household level, In D. Maiti, F. Castellacci, \& A. Melchior (Eds.), Digitalisation and development: issues for India and Beyond, Springer (forthcoming).

OECD. (2018). Economic outlook for Southeast Asia, China and India 2018-Update: Promoting opportunities in E-commerce. Paris: OECD Publishing. https://doi.org/10.1787/9789264302990en.

Parayil, G. (2005). The digital divide and increasing returns: Contradictions of informational capitalism. The Information Society, 21, 41-51.

Poushter, J., Bishop, C., \& Chwe, H. (2018). Social media use continues to rise in developing countries but plateaus across developed ones. Pew Research Center: Global Attitudes Survey.

PRICE. (2016), 'Household Survey on India's Citizen Environment \& Consumer Economy'. ICE $360^{\circ}$ survey-2016. http://www.ice360.in/en/projects/what-are-ice-360-surveys/upcomingsurvey-ice360o-2016.

Ramanna, K., \& Tahilyani, R. (2012). I paid a bribe (dot) com. Harvard Business School Case, 112(078).

Solow, R. M. (1987). We'd better watch out. New York Times Book Review, 36.

Transparency International. (2017). Corruption perceptions index 2017, Berlin, Germany. https:// www.transparency.org/news/feature/corruption_perceptions_index_2017.

Telecom Regulatory Authority of India (2018), Annual Report - 2017-18, Mahanagar Doorsanchar Bhawan, New Delhi https://main.trai.gov.in/sites/default/files/Annual_Report_21022019.pdf.

Veblen, T. (1915). Imperial Germany and the industrial revolution. New York: Macmillan.

Yousefi, A. (2011). The impact of information and communication technology on economic growth: Evidence from developed and developing countries. Economics of Innovation and New Technology, 20(6), 581-596. 
Open Access This chapter is licensed under the terms of the Creative Commons Attribution 4.0 International License (http://creativecommons.org/licenses/by/4.0/), which permits use, sharing, adaptation, distribution and reproduction in any medium or format, as long as you give appropriate credit to the original author(s) and the source, provide a link to the Creative Commons license and indicate if changes were made.

The images or other third party material in this chapter are included in the chapter's Creative Commons license, unless indicated otherwise in a credit line to the material. If material is not included in the chapter's Creative Commons license and your intended use is not permitted by statutory regulation or exceeds the permitted use, you will need to obtain permission directly from the copyright holder.

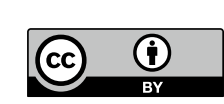

